\title{
Резонансное отражение света оптической решеткой экситонов, сформированной 100 квантовыми ямами InGaN
}

\author{
(C) А.А. Иванов ${ }^{1,2}$, В.В. Чалдышев ${ }^{1}$, Е.Е. Заварин ${ }^{1}$, А.В. Сахаров ${ }^{1}$, В.В. Лундин ${ }^{1}$, А.Ф. Цацульников ${ }^{3}$ \\ ${ }^{1}$ Физико-технический институт им. А.Ф. Иоффе Российской академии наук, \\ 194021 Санкт-Петербург, Россия \\ ${ }^{2}$ Санкт-Петербургский политехнический университет Петра Великого, \\ 195251 Санкт-Петербург, Россия \\ ${ }^{3}$ Научно-технологический центр микроэлектроники и субмикронных гетероструктур Российской академии наук, \\ 194021 Санкт-Петербург, Россия \\ E-mail: aleksei98.ivanov@gmail.com, chald.gvg@mail.ioffe.ru
}

Поступила в Редакцию 12 апреля 2021 г.

В окончательной редакции 19 апреля 2021 г.

Принята к публикации 19 апреля 2021 г.

Исследованы оптические свойства структуры с периодической системой из 100 квантовых ям InGaN, разделенных туннельно-непрозрачными барьерами GaN при комнатной температуре. Периодичность структуры соответствовала брэгговскому условию дифракции на частоте экситонов в квантовых ямах. Численное моделирование с использованием матриц переноса дало адекватное количественное соответствие экспериментальным результатам. Модель включала резонансный отклик А, В и С экситонов в квантовых ямах и учет оптического поглощения в барьерах и буферном слое. Определены параметры излучательного и безызлучательного затухания экситонов в квантовых ямах InGaN.

Ключевые слова: резонансная брэгговская структура, квантовые ямы, экситоны, экситонный резонанс, брэгговский резонанс, нитрид галлия.

DOI: 10.21883/FTP.2021.09.51286.13

\section{1. Введение}

Периодическая модуляция диэлектрической проницаемости среды приводит к брэгговской дифракции распространяющихся в ней электромагнитных волн. Такая модуляция может быть обеспечена как за счет изменения показателя преломления в слоистых структурах (брэгговские диэлектрические отражатели), так и за счет электронных возбуждений, например экситонов в периодической системе квантовых ям (КЯ). Такие периодические структуры КЯ часто называются резонансными брэгговскими структурами (РБС). КЯ в РБС отделены друг от друга туннельно-непрозрачными барьерами, которые также препятствуют электростатическому взаимодействию между экситонами, локализованными в разных ямах. Тем не менее квазидвумерные экситоны взаимодействуют друг с другом, так как они связаны общим электромагнитным полем. В РБС электромагнитное связывание индивидуальных экситонов приводит к формированию суперизлучательной оптической моды. Так, для системы $N$ КЯ в периодической брэгговской последовательности суперизлучательная мода имеет увеличенную в $\mathrm{N}$ раз скорость радиационного затухания [1]. Технологические достижения в области эпитаксиального выращивания высококачественных многослойных гетероструктур позволили получить экспериментальное подтверждение формирования суперизлучательной оптической моды на примере РБС с КЯ CdTe/CdMgTe [2,3], CdTe/CdZnTe [4], GaAs/InGaAs [5,6], GaAs/AlGaAs [7-10] и InGaN/GaN [11-16]. В частности, было обнаружено ре- зонансное усиление амплитуды экситон-поляритонного отражения и одновременное подавление оптического поглощения. Поскольку экситоны в КЯ чувствительны к внешним воздействиям, например приложению электрического поля, то открывается возможность управлять отражением света, управляя параметрами экситонного резонанса в среде.

Наиболее важными физическими параметрами в реализации явления коллективного возбуждения системы экситонов светом являются энергия связи экситонов и их радиационное затухание. В относительно узкозонных полупроводниковых материалах, таких как, например, $\mathrm{GaAs}$, энергия связи экситона значительно меньше тепловой энергии при комнатной температуре. Поэтому РБС на основе таких материалов демонстрируют существенный резонансный отклик исключительно при криогенных температурах (см. [4-10]). Однако это ограничение можно преодолеть, создавая РБС на основе широкозонных материалов семейства $\mathrm{GaN}$ с гораздо большей энергией связи экситона по сравнению с традиционными материалами $\mathrm{A}^{\mathrm{III}} \mathrm{B}^{\mathrm{V}}$, например InGaAlN. Энергия связи экситонов в объемном $\mathrm{GaN}$ составляет 26 мэВ [17], поэтому коллективный экситон-поляритонный резонанс в РБС на основе квантовых ям InGaN удается наблюдать при комнатной температуре [11]. Стабильность экситонов в широком диапазоне температур, вплоть до комнатной, является важнейшим фактором для использования суперизлучательной моды экситонных поляритонов в оптических и оптоэлектронных приборах. Важно отметить огромный технологический прогресс в эпитаксии $\mathrm{A}^{\mathrm{III}}-\mathrm{N}$ 
за последнее десятилетие, позволяющий создавать РБС $\mathrm{GaN} / \mathrm{InGaN} \mathrm{c} \mathrm{большим} \mathrm{числом} \mathrm{периодов.}$

В данной статье мы представляем результаты экспериментального исследования оптических свойств РБС, состоящей из 100 КЯ InGaN, разделенных барьерами GaN. Предложенный нами теоретический анализ позволяет оценить основные параметры экситонов в КЯ и количественно описать усиление отражения, связанное с формированием суперизлучательной экситонполяритонной моды.

\section{2. Образец и методика эксперимента}

Исследуемая РБС на основе 100 КЯ InGaN (рис. 1) изготовлена с использованием метода газофазной эпитаксии из металлоорганических соединений. Рост производился на квазиподложках (темплатах) $\mathrm{GaN} / \mathrm{Al}_{2} \mathrm{O}_{3}$ с толщиной слоя $\mathrm{GaN} \sim 3$ мкм с использованием стандартных источников элементов $\mathrm{A}^{\mathrm{III}}$ и $\mathrm{B}^{\mathrm{V}}$ группы триметилгаллия, триметилиндия и аммиака. Для обеспечения качества материала выращивание $\mathrm{GaN}$-барьеров производилось при высокой температуре $\left(1030^{\circ} \mathrm{C}\right)$ с использованием водорода в качестве несущего газа, выращивание InGaN КЯ производилось при $780^{\circ} \mathrm{C}$ и давлении 200 мбар с использованием азота в качестве основного несущего газа, при этом добавлялся небольшой ( 1\% от общего расхода) поток водорода для подавления кластеризации индия и снижения неоднородного уширения в КЯ. Номинальный период структуры составляет $d=74$ нм, толщина КЯ $\sim 2$ нм.

Вращение подложки во время процесса роста не использовалось, поэтому существующий градиент температур и потоков реагентов приводит к тому, что структура имеет неоднородность толщины слоя и концентрации In, по площади подложки, следовательно, оптические свойства разных областей образца отличаются друг от друга.

Намеренно созданная неоднородность структуры обеспечила разное спектральное положение пика брэггов-

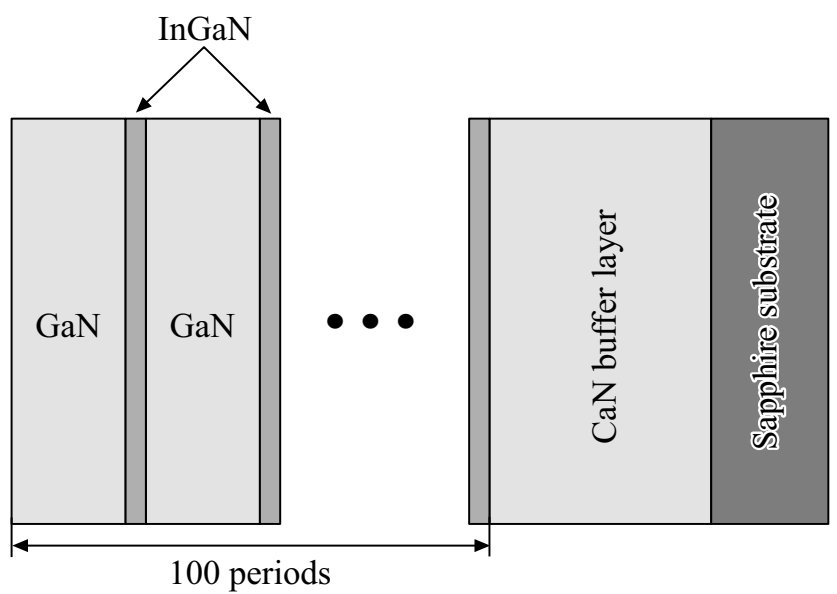

Рис. 1. Дизайн структуры.

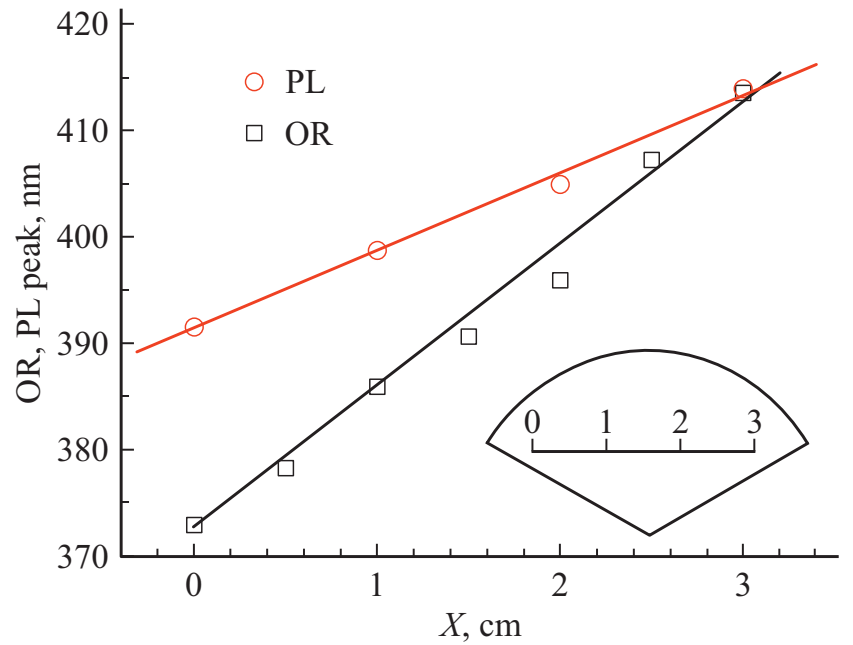

Рис. 2. Измеренное спектральное положение максимума фотолюминесценции (PL) и оптического отражения (OR) при нормальном падении света в зависимости от координаты. Линии проведены для удобства восприятия.

ской дифракции и максимума люминесценции в разных частях структуры (рис. 2). Такие особенности образца обеспечивают возможность исследования свойств как при совпадении брэгговского и экситонного резонансов, так и при их расхождении. Дополнительным инструментом настройки является угол падения света $\vartheta$, поскольку параметры экситонов слабо зависят от угла падения света, а длина волны брэгговского резонанса $\lambda_{\mathrm{Br}}$ подчиняется формуле

$$
\lambda_{\mathrm{Br}}=2 d \sqrt{n_{\mathrm{eff}}^{2}-\sin ^{2} \varphi},
$$

где $n_{\text {eff }}$ - эффективный показатель преломления среды. Спектры оптического отражения и пропускания измерялись для различных углов падения света от 20 до $60^{\circ}$. Измерения проводились для $s$ и $p$ поляризаций при комнатной температуре. В качестве источника света использовалась дейтериевая лампа фирмы „Hamamatsu Photonics K.K.“ модели L6565, которая позволяет получить излучение в видимом и ближнем ультрафиолетовом диапазонах. Свет от источника пропускался через поляризатор, в качестве которого применялась призма Глана-Тейлора, и с помощью линз из кварцевого стекла фокусировался на образце. Для транспорта света от образца к спектрометру использовалось оптическое волокно Ocean Optics типа „solarization resistant". Для измерения спектров фотолюминесценции использовалось возбуждение $\mathrm{He}-\mathrm{Cd}$-лазером (325 нм). Регистрация спектров осуществлялась спектрометром Ocean Optics HR4000.

\section{3. Детали расчета}

Теоретический анализ оптических свойств РБС с КЯ $\mathrm{InGaN}$ выполнялся с использованием метода матриц 
переноса, в котором каждый слой и граница раздела соответствуют матрице $\hat{M} 2 \times 2$, связывающей напряженность электрического поля волн, распространяющихся направо $\left(E^{+}\right)$и налево $\left(E^{-}\right)$:

$$
\left(\begin{array}{c}
E_{\text {right }}^{+} \\
E_{\text {right }}^{-}
\end{array}\right)=\hat{M}\left(\begin{array}{c}
E_{\text {left }}^{+} \\
E_{\text {left }}^{-}
\end{array}\right) \text {. }
$$

Элементы матрицы переноса можно представить, используя амплитудные коэффициенты отражения $r_{1}, r_{2}$ и пропускания $t_{1}, t_{2}$, соответствующие падению волны на структуру слева и справа соответственно:

$$
\hat{M}=\frac{1}{t_{2}}\left(\begin{array}{cc}
t_{1} t_{2}-r_{1} r_{2} & r_{2} \\
-r_{1} & 1
\end{array}\right) .
$$

Результирующая матрица переноса всей РБС получается путем перемножения матриц каждого слоя и интерфейса. Матрица переноса через интерфейс имеет вид

$$
\hat{M}_{\text {int }}\left(n_{2}, n_{1}\right)=\frac{1}{1-\rho}\left(\begin{array}{cc}
1 & -\rho \\
-\rho & 1
\end{array}\right), \quad \rho=\frac{n_{1}-n_{2}}{n_{1}+n_{2}}
$$

В случае наклонного падения в матрице переноса через интерфейс необходимо заменить $n_{1,2}$ на $n_{1,2} \cos \theta_{1,2}$ и $n_{1,2} / \cos \theta_{1,2}$ для $s$ и $p$ поляризации соответственно, где $\theta$ - угол распространения волы в соответствующем слое с показателем преломления $n$, связанный с углом падения соотношением Снеллиуса.

Матрица переноса через КЯ строится на основе формул экситонного отражения и пропускания [1]:

$$
r=\frac{i \Gamma_{0}}{\omega_{0}-\omega-i\left(\Gamma+\Gamma_{0}\right)}, \quad t=1+r
$$

где $t$ - амплитудный коэффициент пропускания; $r-$ амплитудный коэффициент отражения; $\omega_{0}$ - резонансная частота экситона, перенормированная с учетом экситон-фотонного взаимодействия; $\omega_{0}$ - частота падающей световой волны; $\Gamma_{0}$ и $Г$ - константы радиационного и нерадиационного затухания экситона в одиночной КЯ соответственно. В результате чего, если ввести эффективную восприимчивость $S=\Gamma_{0} /\left(\omega_{0}-\omega-i \Gamma\right)$, имеем

$$
\hat{M}=\left(\begin{array}{cc}
1+i S & i S \\
-i S & 1-i S
\end{array}\right)
$$

Матрица переноса через барьер толщиной $d$ с волновым вектором $q$ без учета поглощения имеет диагональный вид:

$$
\hat{M}_{\text {layer }}=\left(\begin{array}{cc}
e^{i q d} & 0 \\
0 & e^{-i q d}
\end{array}\right) .
$$

В случае наклонного падения в матрице переноса через барьер необходимо заменить $d$ на $d \cos \theta$.

Для более качественного описания оптических свойств РБС в области энергий фотонов, близкой к краю запрещенной зоны, необходимо учесть спектральную зависимость коэффициента поглощения, известную как эмпирическое правило Урбаха:

$$
\alpha=\alpha_{0} \exp \left[\frac{E-E_{g}}{E_{\mathrm{U}}}\right],
$$

где $\alpha_{0}-$ константа, $E_{\mathrm{U}}-$ энергия Урбаха.

\section{4. Результаты и обсуждение}

На рис. 3 и 4 представлены экспериментальные (1) и расчетные $(2,3)$ спектры отражения и пропускания для $s$-поляризованного света, падающего под углом $20^{\circ}$. Угол падения света подобран так, чтобы наблюдалось

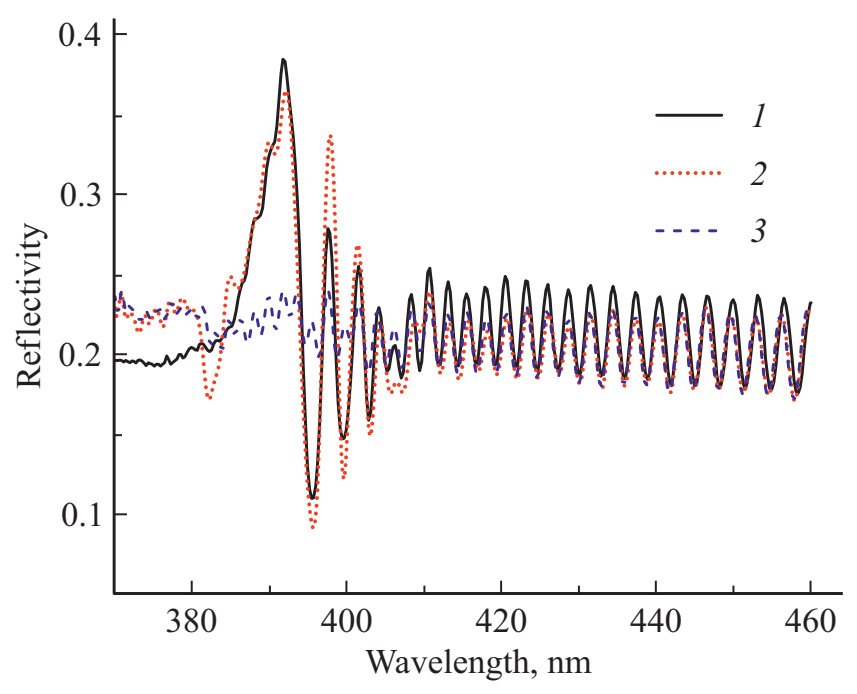

Рис. 3. Спектр отражения: эксперимент (1), расчет с учетом (2) и без учета (3) экситонов. Угол падения света $20^{\circ}, s$-поляризация. (Цветной вариант рисунка представлен в электронной версии статьи).

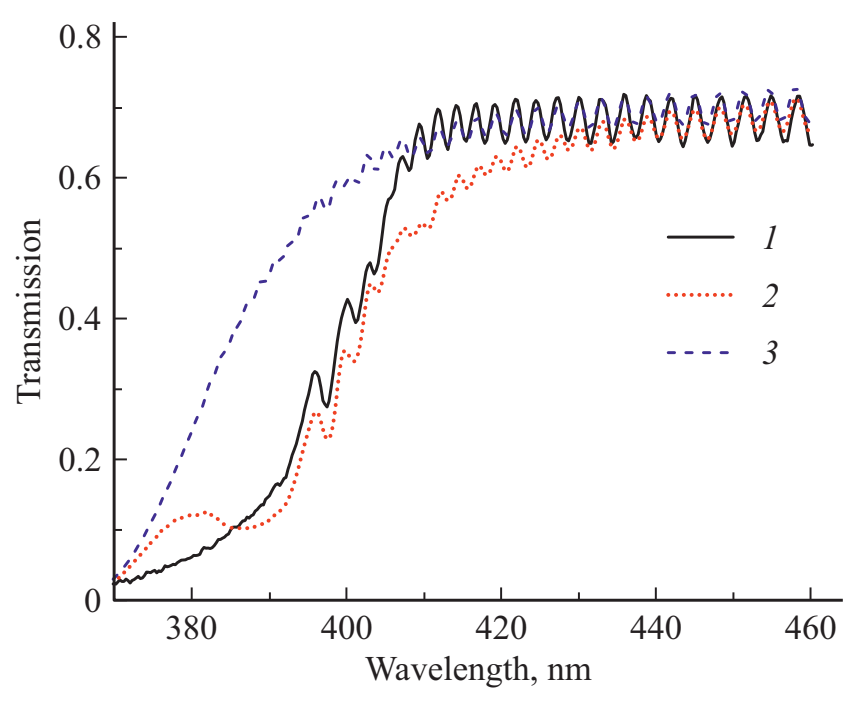

Рис. 4. Спектр пропускания: эксперимент (1), расчет с учетом (2) и без учета (3) экситонов. Угол падения света $20^{\circ}$, $s$-поляризация. 
максимальное увеличение коэффициента отражения, обусловленное совпадением брэгговского и экситонного резонанса. Расчет выполнялся как с учетом экситонного резонанса (2), так и без него (3). Сравнение спектров позволяет сделать вывод, что существует модуляция отражения, вызванная контрастом показателя преломления в InGaN/GaN РБС, но периодическая решетка экситонов дает основной вклад в отражение света.

В спектре отражения наблюдается доминирующая особенность на длине волны 391.6 нм, обусловленная брэгговской дифракцией света на системе квантовых ям. Из-за отклонений толщины слоев структуры от точной периодичности главный брэгговский максимум сопровождается дополнительной дифракционной картиной. Для учета и описания этого явления в расчете толщина структуры задавалась по 10 подряд расположенных квантовых ям одной толщины в данной выборке.

Помимо резонансных особенностей на рис. 3 и 4 наблюдаются осцилляции Фабри-Перо, которые имеют значительную амплитуду в длинноволновой области спектра и затухают в области коротких длин волн при приближении к краю фундаментального поглощения $\mathrm{GaN}$. Осцилляции Фабри-Перо возникают в результате интерференции световых лучей, отраженных от границ всей эпитаксиальной структуры, включающей в себя РБС и буферный слой. Расположение и амплитуда интерференционных осцилляций в области прозрачности среды хорошо описывается в рамках использованной нами модели.

Для того чтобы избежать существенных расхождений между расчетным и экспериментальным спектрами пропускания в коротковолновой части спектра, необходимо было учесть оптическое поглощение в барьерах и буферном слое. Наилучшее соответствие эксперименту достигается, когда энергия Урбаха составляет 80 мэВ. Для устранения оставшихся расхождений в области 380 нм, по-видимому, необходимо также учитывать поглощение в непрерывном спектре состояний КЯ [18].

Мы учли тот факт, что валентная зона в полупроводниках со структурой вюрцита расщеплена на три близко расположенных подзоны, поэтому в расчете использовались экситоны А, В и С типа с энергиями $3.15,3.2$ и 3.23 эВ соответственно. Энергии экситонов подбирались исходя из наилучшего соответствия экспериментальным данным. Наиболее подходящие параметры расчетов: параметр радиационного уширения $-0.18 \pm 0.02$ мэВ для А и В экситонов, $0.1 \pm 0.02$ мэВ для С экситона, параметр безызлучательного уширения экситонов при комнатной температуре составляет 50 мэВ.

Полученные нами параметры квазидвумерных экситонов в системе $\mathrm{GaN} / \mathrm{InGaN}$ находятся в разумном соответствии с результатами работы $[15]$, в которой исследовалась аналогичная структура с 60 периодами. Однако модель, предложенная авторами в этой работе, включает в себя исключительно А экситон, что, по-видимому, приводит к небольшим переоценкам параметров.
Формирование суперизлучательной моды в РБС при комнатной температуре зависит не только от энергии связи экситона, как было отмечено выше, но и от величины радиационного затухания в сравнении с безызлучательным. Так, например, в КЯ на основе GaAs из-за небольшого радиационного уширения $0.02-0.04$ мэВ [5-10] для создания эффективной РБС требуется большое число периодов даже при низкой температуре, когда безызлучательное затухание $<1$ мэВ. В результате РБС с КЯ GaAs/InGaAs и GaAs/AlGaAs демонстрируют значительное усиление отражения, но из-за безызлучательных процессов, связанных с экситонфононным рассеянием, оказываются непригодными для эффективной работы при комнатной температуре. Более привлекательными являются системы с большим радиационным уширением 0.1 мэВ [4] и $0.12-0.15$ мэВ [2,3] для КЯ $\mathrm{CdTe} / \mathrm{CdZnTe}$ и $\mathrm{CdTe} / \mathrm{CdMgTe}$ соответственно. Однако энергия связи экситона в этих системах меньше, чем в GaN. При этом технология выращивания многопериодных РБС на основе CdTe недостаточно развита. Указанные обстоятельства позволяют предполагать, что управляемые РБС на основе $\mathrm{A}^{3}$-нитридов имеют наилучшие перспективы к внедрению в фотонные и оптоэлектронные устройства, работающие при комнатной температуре.

Таким образом, наше исследование подтверждает, что параметр радиационного затухания для экситонов в КЯ InGaN в $\sim 2$ раза больше, чем в РБС на основе CdTe, и в $\sim 5$ раз больше, чем в системах с КЯ на основе GaAs. Большая энергия связи экситона в системах на основе $\mathrm{GaN}$ позволяет наблюдать суперизлучательную экситон-поляритонную моду при комнатной температуpe, несмотря на достаточно большое безызлучательное затухание.

\section{5. Заключение}

Проведенные исследования показали возможность со-

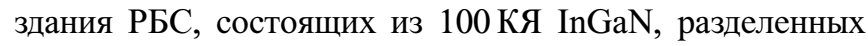
барьерами $\mathrm{GaN}$. Нами экспериментально продемонстрировано резонансное усиление оптического отражения при комнатной температуре в периодической экситонной решетке. Построена количественная модель, описывающая оптические свойства РБС. Получено хорошее согласие экспериментальных спектров с количественными теоретическими расчетами, что позволило определить параметры А, В и С экситонов в КЯ.

\section{Благодарности}

Авторы благодарны М.А. Яговкиной за рентгенодифракционные исследования образца.

\section{Конфрликт интересов}

Авторы заявляют, что у них нет конфликта интересов. 


\section{Список литературы}

[1] Е.Л. Ивченко, А.И. Несвижский, С. Йорда. ФТТ, 36, 2118 (1994).

[2] V.P. Kochereshko, G.R. Pozina, E.L. Ivchenko, D.R. Yakovlev, A. Waag, W. Ossau, G. Landwehr, R. Hellmann, E.O. Göbel. Superlatt. Microstr., 15, 471 (1994).

[3] Е.Л. Ивченко, В.П. Кочерешко, А.В. Платонов, Д.Р. Яковлев, А. Baar, В. Осcау, Г. Ландвер. ФТТ, 39, 2072 (1997).

[4] Y. Merle d'Aubigné, A. Wasiela, H. Mariette, T. Dietl. Phys. Rev. B, 54, 14003 (1996).

[5] G.R. Hayes, J.L. Staehli, U. Oesterle, B. Deveaud, R.T. Phillips, C. Ciuti. Phys. Rev. Lett., 83, 2837 (1999).

[6] M. Hübner, J.P. Prineas, C. Ell, P. Brick, E.S. Lee, G. Khitrova, H.M. Gibbs, S.W. Koch. Phys. Rev. Lett., 83, 2841 (1999).

[7] В.В. Чалдышев, А.С. Школьник, В.П. Евтихиев, Т. Holden. ФТП, 40, 1466 (2006)

[8] D. Goldberg, L.I. Deych, A.A. Lisyansky, Z. Shi, V.M. Menon, V. Tokranov, M. Yakimov, S. Oktyabrsky. Nature Photonics, 3, 662 (2009).

[9] V.V. Chaldyshev, Y. Chen, A.N. Poddubny, A.P. Vasil'ev, Z. Liu. Appl. Phys. Lett., 98, 073112 (2011).

[10] В.В. Чалдышев, Е.В. Кунделев, Е.В. Никитина, А.Ю. Егоров, А.А. Горбацевич. ФТП, 46, 1039 (2012)

[11] V.V. Chaldyshev, A.S. Bolshakov, E.E. Zavarin, A.V. Sakharov, W.V. Lundin, A.F. Tsatsulnikov, M.A. Yagovkina, T. Kim, Y. Park. Appl. Phys. Lett., 99, 251103 (2011)

[12] А.С. Большаков, В.В. Чалдышев Е.Е. Заварин, А.В. Сахаров, В.В. Лундин, А.Ф. Цацульников, М.А. Яговкина. ФТТ, 55, 1706 (2013).

[13] В.В. Чалдышев, А.С. Большаков, Е.Е. Заварин, А.В. Сахаров, В.В. Лундин, А.Ф. Цацульников. ФТТ, 49, 6 (2015).

[14] А.С. Большаков, В.В. Чалдышев, Е.Е. Заварин, А.В. Сахаров, В.В. Лундин, А.Ф. Цацульников. ФТТ, 50, 1451 (2016).

[15] A.S. Bolshakov, V.V. Chaldyshev, E.E. Zavarin, A.V. Sakharov, W.V. Lundin, A.F. Tsatsulnikov, M.A. Yagovkina. J. Appl. Phys., 121, 133101 (2017).

[16] A.A. Ivanov, V.V. Chaldyshev, E.E. Zavarin, A.V. Sakharov, W.V. Lundin, A.F. Tsatsulnikov. J. Phys.: Conf. Ser., 1697 012153 (2020).

[17] A.V. Rodina, M. Dietrich, A. G"oldner, L. Eckey, A. Hoffmann, Al.L. Efros, M. Rosen, B.K. Meyer. Phys. Rev. B, 64, 115204 (2001).

[18] P.C. Klipstein, N. Apsley. J. Phys. C: Solid State Phys., 19, 6461 (1986).

Редактор Г.А. Оганесян

\section{Resonant light reflection from an optical lattice of excitons formed by 100 InGaN quantum wells}

\author{
A.A. Ivanov ${ }^{1,2}$, V.V. Chaldyshev ${ }^{1}$, E.E. Zavarin ${ }^{1}$, \\ A.V. Sakharov ${ }^{1}$, W.V. Lundin ${ }^{1}$, A.F. Tsatsulnikov ${ }^{3}$ \\ ${ }^{1}$ loffe Institute, \\ 194021 St. Petersburg, Russia \\ 2 Peter the Great St. Petersburg Polytechnic University, \\ 195251 St. Petersburg, Russia \\ ${ }^{3}$ Submicron Heterostructures for Microelectronics, \\ Research and Engineering Center, \\ Russian Academy of Sciences, \\ 194021 St. Petersburg, Russia
}

Abstract Optical properties of a structure with a periodic system of $100 \mathrm{InGaN}$ quantum wells (QWs) separated by nontunneling GaN barriers have been investigated at room temperature. The structure periodicity corresponded to the Bragg diffraction condition at the frequency of the QW excitons. Numerical modeling using transfer matrices gave a quantitatively accurate fit of the experimental results. The model included the resonance response of $\mathrm{A}, \mathrm{B}$, and $\mathrm{C}$ excitons in QWs and an optical absorption tail in the barriers and buffer layer. We have determined the radiative and non-radiative broadening of the excitons in the InGaN QWs. 